\title{
Chapter 14 \\ Radioactive Contamination of Ostriches \\ in a Potentially Permanent Evacuation Zone
}

\author{
Hiroshi Ogawa, Hidehiko Uchiyama, Koji Masuda, Takeshi Sasaki, \\ Tadao Watanabe, Toshiaki Tomizawa, and Schu Kawashima
}

\begin{abstract}
We measured the concentrations of radioactive cesium $\left({ }^{134} \mathrm{Cs},{ }^{136} \mathrm{Cs}\right.$, and ${ }^{137} \mathrm{Cs}$ ) in muscles and internal organs of ostriches that had been contaminated by radioactive materials from the Fukushima Daiichi Nuclear Power Station. Although the ostriches were given uncontaminated feed and water throughout the study, radionuclide could not be eliminated completely as the birds consumed soil and plants in the enclosures. However, we found that the amount of radioactive cesium in the ostriches' bodies declined in the first 287 days after capture. This result suggests that keeping the birds in a radiation-free environment is effective in reducing the amount of radioactive cesium in their bodies.
\end{abstract}

Keywords Fukushima nuclear disaster • Ostrich • Radioactive cesium • Internal organs $\bullet$ Muscles

\subsection{Background and Purpose of Research}

The Great East Japan Earthquake of March 11, 2011, triggered an accident at the Fukushima Daiichi Nuclear Power Station, releasing a large amount of radioactive material into the environment. Because of the resulting evacuation, 30 ostriches were abandoned at an ostrich farm approximately $7 \mathrm{~km}$ from the power station (Fig. 14.1). Around 4 months after the accident, half the ostriches had died and some had escaped from the farm. It is believed that, following the earthquake and associated disasters, the abandoned ostriches survived by eating mainly

H. Ogawa $(\bowtie) \bullet$ H. Uchiyama $\bullet$ K. Masuda $\bullet$ T. Sasaki $\bullet$ S. Kawashima

Department of Human and Animal-Plant Relationships, Tokyo University of Agriculture,

Funako, Atsugi, Kanagawa 243-0034, Japan

e-mail: ogawah@nodai.ac.jp

T. Watanabe

The Research Institute of Evolutionary Biology, Kamiyoga, Setagaya, Tokyo 158-0098, Japan

T. Tomizawa

Strauss Co., Ltd., Yoshikawa, Saitama 342-0055, Japan

T. Monma et al. (eds.), Agricultural and Forestry Reconstruction

After the Great East Japan Earthquake, DOI 10.1007/978-4-431-55558-2_14 


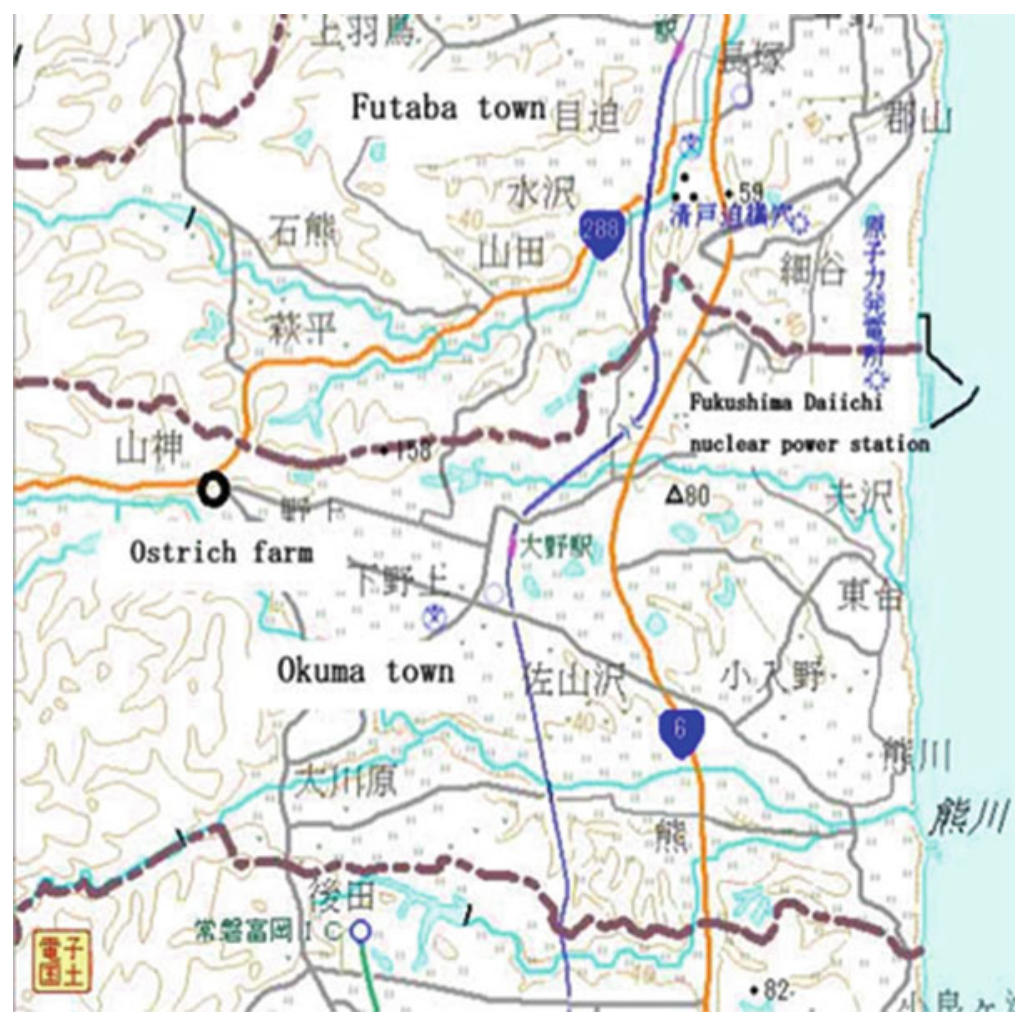

Fig. 14.1 Survey site

radiation-contaminated plants and insects and drinking standing water such as rainwater puddles. We had reason to suspect, therefore, that the radionuclide scattered over the area had accumulated in their bodies. Other livestock left behind were in most cases not permitted to be taken out of the $20-\mathrm{km}$ exclusion zone and as a rule were euthanized. Under these circumstances, we attempted to record the extent to which the escaped ostriches had been contaminated, as well as identify how the concentrations of radiation inside their bodies changed when they were provided with uncontaminated feed. We believed such a study could help elucidate the extent to which animals in general had been internally contaminated, the effects on their health caused by the contamination, and the process by which it could be decreased or eliminated. We also believed the study could help identify some key principles to be applied when resuming agricultural production in the affected areas. 


\subsection{Materials and Methods}

\subsubsection{The Ostriches Examined}

The study was conducted on five male ostriches and one female ostrich (African Black; Fig. 14.2) that had been recaptured after escaping from the farm in the town of Okuma in Futaba County, Fukushima Prefecture.

\subsubsection{Handling and Feeding Methods}

The ostriches were kept in $180-\mathrm{m}^{2}$ enclosures with a $32-\mathrm{m}^{2}$ roofed area (Fig. 14.3), either on their own, or with a maximum of one male and two females per enclosure (one female ostrich that died during the study was not included in the results). Commercial dog food and clean well water were supplied as feed and drinking water. Food and drinking water were replenished once per week. However, in March 2012 they were replenished once per fortnight.

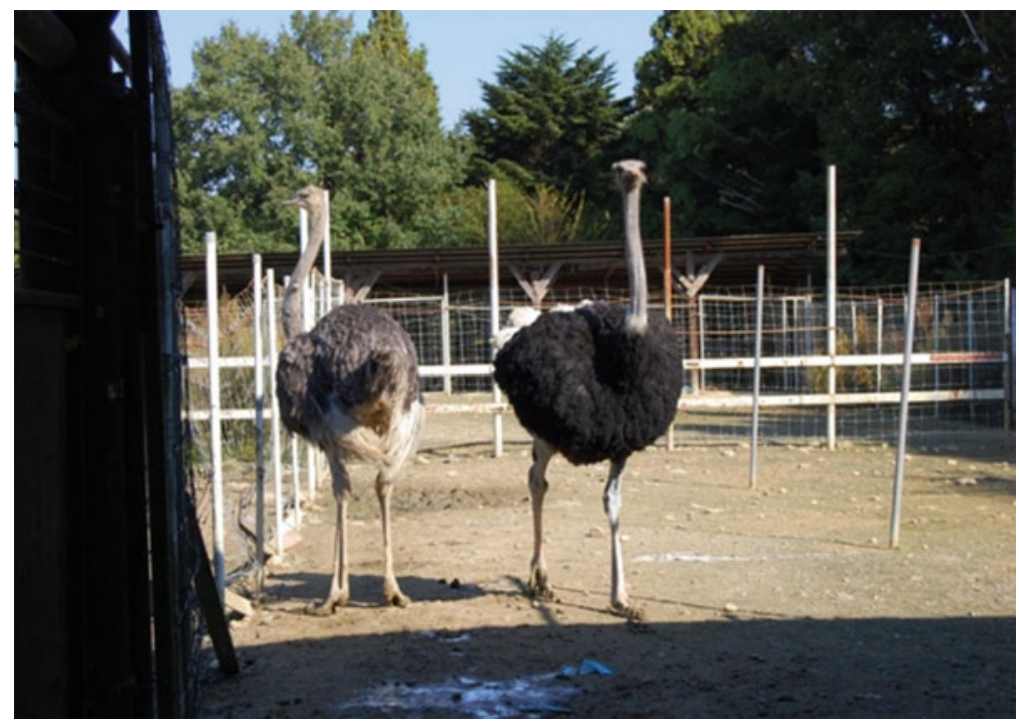

Fig. 14.2 Two of the ostriches examined 


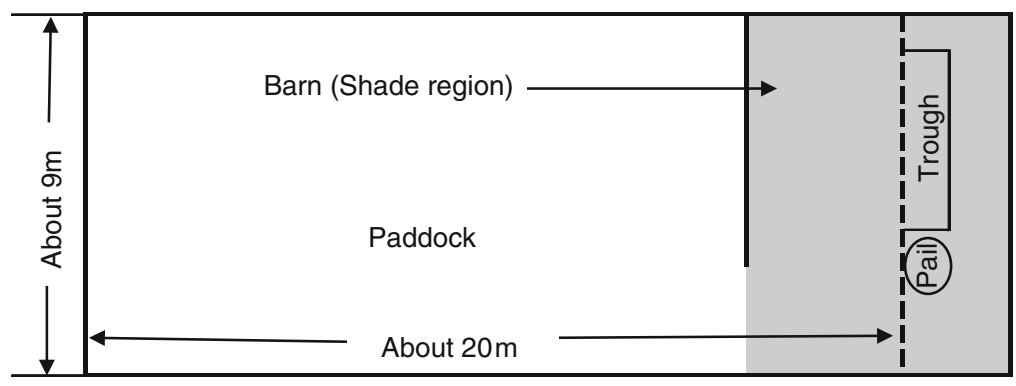

Fig. 14.3 Overview of enclosure

Table 14.1 Dates of capture and examination

\begin{tabular}{l|l|l|l|l}
\hline Recapture day & Sex & Date examined & $\begin{array}{l}\text { Days from recapture } \\
\text { to examination }\end{array}$ & Age in months \\
\hline January 12, 2012 & Male & March 27, 2012 & 74 & 79 \\
\hline January 13, 2012 & Male & February 16, 2012 & 34 & 66 \\
\hline January 13, 2012 & Male & October 26, 2012 & 287 & 180 \\
\hline January 13, 2012 & Female & February 8, 2013 & 392 & $60-84$ \\
\hline January 13, 2012 & Male & February 21, 2013 & 405 & $60-84$ \\
\hline May 29, 2012 & Male & May 25, 2013 & 361 & Unknown \\
\hline
\end{tabular}

\subsubsection{Study Method}

The number of days between capturing and examining the ostriches ranged from 34 to 405 days (Table 14.1). Before being examined, the ostriches were restrained and euthanized via injection of anesthetic (somnopentyl) into the neck vein.

\subsubsection{Body Measurement and Collection of Samples}

After taking body measurements of the dead ostriches, including total body length, maximum wing length, wingspan, tail length, exposed beak length, total beak length, total head length, beak width, toe length, toe span, claw length, and tarsus length, the birds were dissected and samples collected.

\subsubsection{Radiation Measurement}

We took samples for radiation measurement purposes from the chest muscle, subcutaneous chest fat, lower and upper leg muscles, brain, thyroid, liver, spleen, crop, gizzard, stomach content, rectal content, pancreas, heart, lungs, kidneys, adrenal 
gland, testes or ovaries, egg yolk, egg white, and eggshell. Plants, soil, and drinking water were also collected as environmental samples. We measured radionuclide by placing samples in a 100-ml vessel and using a germanium semiconductor detector to identify gamma-ray nuclides and the concentration of radioactive material $(\mathrm{Bq} / \mathrm{kg})$ via the gamma-ray spectrometer method.

\subsection{Research Findings}

\subsubsection{Ambient Dose}

The ambient radiation doses measured during the study were as follows:

March 16, 2012: $4.6 \mu \mathrm{Sv} / \mathrm{h}$

March 27, 2012: $4.0 \mu \mathrm{Sv} / \mathrm{h}$

October 24, 2012: $3.4 \mu \mathrm{Sv} / \mathrm{h}$

February 8, 2013: $2.3 \mu \mathrm{Sv} / \mathrm{h}$

February 21, 2013: $2.4 \mu \mathrm{Sv} / \mathrm{h}$

May 25, 2013: $2.0 \mu \mathrm{Sv} / \mathrm{h}$

Thus, dosage per hour gradually declined with time.

\subsubsection{Body Measurements}

The ostriches examined had an average total body length of $232 \mathrm{~cm}$, maximum wing length of $123 \mathrm{~cm}$, wingspan of $231 \mathrm{~cm}$, tail length of $30 \mathrm{~cm}$, exposed beak length of $6 \mathrm{~cm}$, total beak length of $9 \mathrm{~cm}$, total head length of $19 \mathrm{~cm}$, beak width of $7 \mathrm{~cm}$, toe length of $19 \mathrm{~cm}$, toe span of $24 \mathrm{~cm}$, claw length of $4 \mathrm{~cm}$, and tarsus length of $45 \mathrm{~cm}$. Comparison of measurements such as beak, head, toe, and tarsus length did not reveal any significant difference in physique between males and females. However, the male population surveyed included physically small birds, and variance in growth and physical condition between specimens was observed.

\subsubsection{Pathological Findings Relating to Internal Organs}

The state of the digestive organs (stomach, gizzard, intestines), trunk muscle, bone (cranium), respiratory organs (trachea, lungs), circulatory organs (blood vessels, heart), and various tissues (thyroid, etc.) showed the specimens to be in relatively good health given the fact that they had been wandering outdoors for some time. 


\subsubsection{Radionuclide in Test Samples}

Radioactive cesium in the ostriches' living environment was 2,300-75,000 Bq/kg in the soil and 1,200-4,400 Bq/ $\mathrm{kg}$ in nearby plants. No radiation was detected in drinking water, despite adulteration with rainwater.

Radioactive cesium in stomach content ranged from 3,100 to $20,000 \mathrm{~Bq} / \mathrm{kg}$, despite the fact that the ostriches were given uncontaminated feed, likely from consumption of soil or plants within or outside the enclosure, rather than the clean feed administered. The highest concentration of radioactive cesium was found in rectal content, ranging from 11,000 to $65,000 \mathrm{~Bq} / \mathrm{kg}$, likely the result of concentration in the digestive organs.

In general, however, levels of radioactive cesium in the bodies of the ostriches tended to be low in the internal organs and higher in the skeletal muscles. In contrast to concentrations of $1,100-6,700 \mathrm{~Bq} / \mathrm{kg}$ in the gizzard and heart, which are composed almost completely of internal muscle tissue, cesium was highly concentrated in the skeletal chest and leg muscles at 2,300-27,000 Bq/kg. Concentration in other internal organs ranged from 500 to $6,700 \mathrm{~Bq} / \mathrm{kg}$. Radioactive cesium contained in eggs was 500-1,900 Bq/kg in the whites, 200-740 Bq/kg in the yolks, and 70-220 Bq/ $\mathrm{kg}$ in the shells. The concentration in the whites was therefore 2.5 to 2.7 times that in the yolks, likely related to the high proportion of fat in the yolk. A minute amount of potassium-40 was also detected in the kidneys, heart, testes, and thyroid.

Although the ostriches were given uncontaminated feed and water throughout the study, radionuclides could not be eliminated completely as the birds consumed soil and plants in the enclosures. However, we found that the amount of radioactive cesium in the ostriches' bodies declined in the first 287 days after capture, before leveling off with slight fluctuations, suggesting that keeping the birds in a radiationfree environment is effective in reducing the amount of radioactive cesium in their bodies.

\subsection{Conclusion}

Although radioactive cesium emitted by the Fukushima nuclear accident was detected in the bodies of ostriches abandoned in the town of Okuma, the level declined when the birds were given clean feed and water. As outlined in the Bergonié-Tribondeau law (Bergonié and Tribondeau 1906), it is known that the effect of radiation on biological tissue is greater in cells that undergo frequent cell division, cells that will undergo numerous cell divisions in future, and undifferentiated cells ${ }^{1}$. Although much is still unknown regarding long-term exposure to $1 \mathrm{C}$ radiation in humans, studies on the impact of the Chernobyl nuclear accident indicate effects such as an increase in tumors in children, particularly in the occurrence of thyroid cancer, and a negative impact on pregnant women and the development of fetuses (Investigation Committee for Chernobyl nuclear power plant accident, 
etc. of the House of Representatives 2011). To eliminate the effect of radionuclides, it is important that the living environment is kept as free of radiation as possible and that uncontaminated food is consumed on an ongoing basis.

Acknowledgments This research received funding from the Society for Livestock Studies. We thank Dr. Daishiro Yamagiwa, who provided tremendous assistance for this study.

Open Access This chapter is distributed under the terms of the Creative Commons Attribution Noncommercial License, which permits any noncommercial use, distribution, and reproduction in any medium, provided the original author(s) and source are credited.

\section{References}

Bergonié J, Tribondeau L (1906) De Quelques Résultats de la Radiotherapie et Essai de Fixation d'une Technique Rationnelle. C R Seances Acad Sci 143:983-985

Investigation committee for Chernobyl Nuclear Power Plant Accident, etc. of the House of Representatives (2011) A report by investigation committee for Chernobyl nuclear power plant accident, etc. of the House of Representatives. http://www.shugiin.go.jp/itdb_annai.nsf/html/ statics/shiryo/201110cherno.htm, 2 Sept 2014 